\title{
Embedding knowledge transfer in digital citizen engagement in South Africa: Developing digital literacy
}

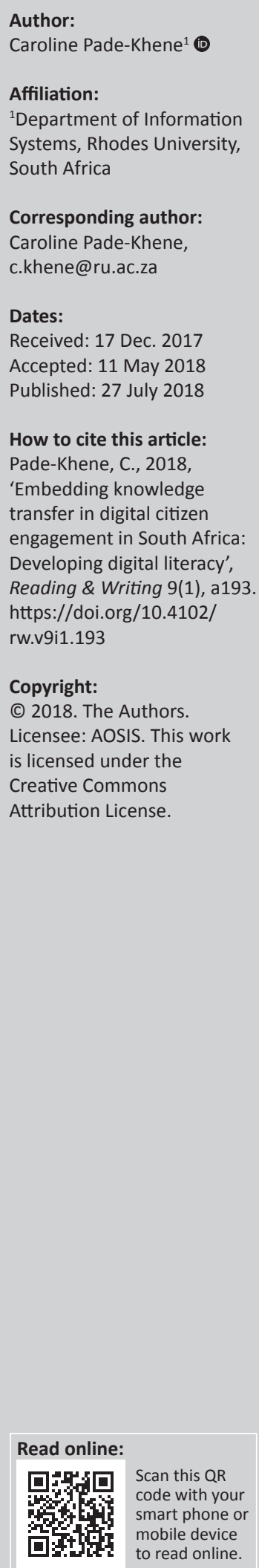

Basic service delivery is a fundamental right for all South Africans, especially vulnerable groups. Effective and efficient channels of communication between multi-stakeholder groups involved and affected by service delivery are essential. Digital citizen engagement has recently emerged as a key approach for supporting two-way communication between citizens and the government. It is essential for building evidence-based data to engage with government and apply social accountability measures to lobby for the provision of basic services. Key to building capacities and learning, is developing the abilities of both local government and citizens to become digitally literate (including civic and responsiveness literacy), in order to realise and action the true benefits of digital citizen engagement. This research set out to identify the roles of digital literacy in digital citizen engagement, and how it may be embedded in knowledge transfer processes for implementing digital citizen engagement initiatives. A pragmatist philosophical approach was applied: studying, observing and reflecting on actions in the MobiSAM case study. Using Szulanski's four-stage model of knowledge transfer, key focus areas for developing digital literacy were identified, contributing to a Quadruple-E process of: (1) explore, (2) enable, (3) engage and (4) embed. Practices identified in the MobiSAM case study are provided as suggestions for each phase, with an indication of possible constraints that may be experienced in the knowledge transfer and digital literacy development process - a potential guideline for developing digital literacy in digital citizen engagement initiatives. The process for knowledge transfer and developing digital literacy that was identified in this article provides a guideline for future implementation of digital citizen engagement initiatives in resource-constrained contexts.

\section{Introduction}

Although South Africa possesses a progressive legislative framework for service delivery, when it comes to implementation at the local level, the reality is different (Tissington et al. 2008). Especially disconcerting is the lack of services in predominantly poor communities, rural areas and informal settlements of South Africa (Algotsson et al. 2009). Service distribution inequalities emanated from the past; apartheid legacy have left high levels of imbalance in access to resources, infrastructure and social services (Nnadozie 2013; Tissington et al. 2008). A lack of service delivery in these areas infringes on the rights of vulnerable citizens to basic services, such as clean water, sanitation, electricity and housing . Particularly pertinent to service delivery in South Africa is the need to institute effective and efficient channels of communication between multi-stakeholder groups involved and affected by service provision processes. It is essential that local government engages in two-way interaction, giving citizens a stake in decision-making with the objective of improving service delivery outcomes, especially in marginalised contexts. Engagement is vital in policy-making as it informs people of public issues, drives citizens towards a common ground that can break legislative deadlocks and increases the accountability of elected officials. Citizens in vulnerable contexts are often unaware of their rights, nor do they have the capacity to effectively engage with government.

Citizen engagement is widely promoted as a 'game changer' for development (Gaventa \& Barrett 2012), as the voiceless become empowered to evoke change in society. Building citizen engagement should be examined by identifying ways to increase participation, such as showing results from engagement, designing multiple channels of participation, providing multitiered levels of engagement, reinforcing a sense of civic duty and collectiveness and getting precommitment from citizens (Spada et al. 2015). The concept of citizen engagement and citizen participation is universal and fundamental to supporting accountability and transparency of government service delivery; however, each global context differs in terms of the effectiveness to deliver and voice the needs of citizens and vulnerable groups. Citizen engagement is not a straightforward process, especially in resource-constrained contexts where citizens have not had the capacity and knowledge of their 
rights to hold government accountable. Coupled with this, local government in resource-constrained contexts often do not have the capacity and rightly shaped institutional cultural to engage in such initiatives - resulting in a lack of government responsiveness. Digital citizen engagement (DCE) has emerged over the recent years as a key tool to enable this much needed two-way communication and engagement between citizens and government (Peixoto \& Fox 2016). Digital citizen engagement is defined as (Haikin et al. 2016): "The use of new media/digital information and communication technologies to create or enhance the communication channels which facilitate the interaction between citizens and governments or the private sector'. Information and communication technology (ICT) is not necessarily a panacea for many challenges being faced in the service delivery sector in developing countries; however, an ICT-enabled environment could be one of many significant means to support service delivery. Examples of key initiatives include Ushahidi, FixMyStreet, Maji Voice and MobiSAM. Residents use these platforms to report on service delivery issues, and track the progress in getting them addressed. Digital citizen engagement initiatives can play the role of bringing together the voices of individual reports, and collective action by activists and civil society organisations (CSOs) (illustrated in Figure 1 by Peixoto and Fox [2016]). Typically, a citizen would report a service issue directly to a municipality that remains as an undisclosed individual report, which the general public is unaware of. On the contrary, civil society attempts to lobby for more collective actions on certain issues reported to collective groups, which can at times be isolated and insufficiently reflect the true nature of the service delivery issue in the population. The role of ICTs is to bring together individual and collective action with real-time access to mechanisms to report issues to all stakeholders.

Despite the opportunities that exist with ICT and citizen engagement, the implementation and beneficial realisation of these initiatives by both citizens and government is not easy. Digital citizen engagement projects have not yielded

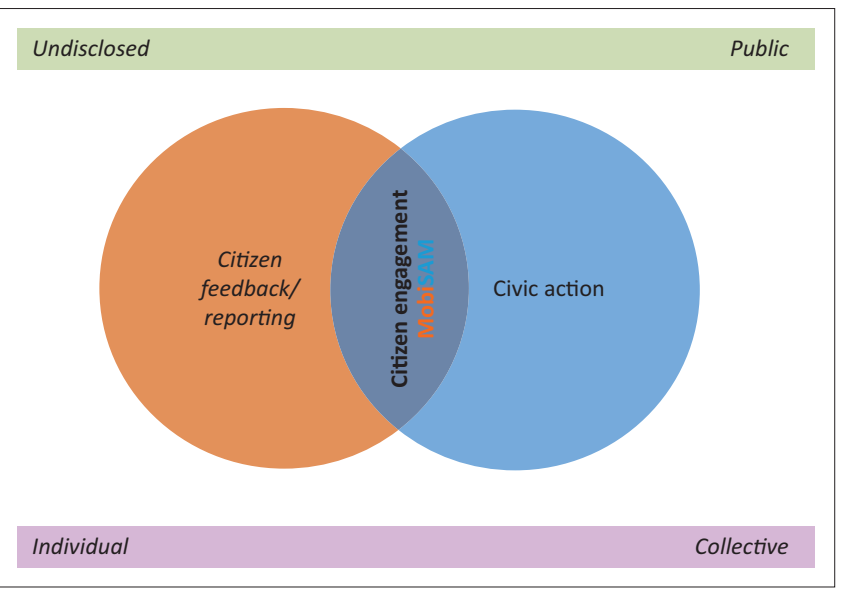

Source: Adapted from Peixoto, T. \& Fox, J., 2016, When does ICT-enabled citizen voice lead to government responsiveness?, World Bank, Washington, DC

FIGURE 1: What citizen engagement means in MobiSAM. the expected benefits to all key stakeholders, resulting in much scepticism around supporting such projects. This is also quite typical of many ICT for development (ICT4D) projects in developing countries. Nevertheless, this does not imply that such projects do not have successful outcomes - these outcomes can only be fully realised when an effort is made to apply endogenous practices to understand institutional forces that support or hinder implementation and sustainability (Mansell 2011). The failures and challenges should be seen by researchers and practitioners as opportunities to learn from them, unlearn wrong practices and apply incremental changes or develop possible mechanisms and theories to address these specific failures (Dodson, Sterling \& Bennett 2012; Pade-Khene \& Lannon 2017).

The process of learning from failures, and unlearning existing practices that hinder progress, requires a process of continuous engagement with key stakeholders in a DCE initiative, that is, government and citizens. Toyama (2011) points out three fundamental institutional forces that influence engagement with ICTs in different contexts: differential access, differential capacity and differential motivation. These aspects are often embedded in local practice and context (endogenous practice); therefore, practitioners and researchers need to learn in the local context to obtain insight into the factors that influence DCE. Furthermore, they need to engage in participatory approaches with key beneficiaries, allowing multiple perspectives to emerge in an open dialogue of knowledge transfer and incremental learning through a consultative process of decision-making (Ika \& Hodgson 2014; Mansell 2011; Toyama 2015). Key to building capacities and learning is developing the abilities of both local government and citizens to become digitally literate, in order to realise and action the true benefits of DCE. The aim of this article is to present a case for digital literacy development in DCE initiatives in South Africa. The two research questions addressed in this article include the following: (1) What is the role of digital literacy in DCE projects in South Africa? (2) How can digital literacy be embedded in knowledge transfer processes for implementing DCE initiatives?

To set the background for the article, the case for digital literacy and how it is positioned as an outcome of knowledge transfer is discussed in a literature review. Subsequently, a case study of a DCE project called MobiSAM is presented as a reflective case, where a pragmatist approach was applied to investigate the development of digital literacy for DCE. Szulanski's (1996) four-stage model is applied as a foundation to build an iterative process for developing digital literacy in DCE projects at local government level in the South African context. The conclusion summarises the findings and concludes that the process for knowledge transfer and developing digital literacy that is identified in this article can provide a guideline for future implementation of DCE in resource-constrained contexts. 


\section{The role of digital literacy in digital citizen engagement}

Digital literacy emerged from the concept of the digital divide, which has traditionally been used to describe the inequalities that exist between those who can engage in the digital society and those who cannot (Evans \& Gomes 2017). This is quite pertinent in developing countries, where deducing the digital divide was mainly based on aspects of access to technology to participate in society - the first-order effect of the digital divide. Toyama (2015) argues against this limited view of unequal access in the information society, as 'access' not only goes beyond access to technology or infrastructure, but also considers issues of capacity and motivation to effectively and strategically use technology for its intended purpose - in the case of this article, to use technology to participate in citizen engagement. This resulted in what authors call, the secondorder effect of the digital divide - which moves beyond access to also consider social access or the lack of skill to take advantage of ICTs (Evans \& Gomes 2017; Henninger 2017; Huerta \& Sandoval-Almazan 2007). The second-order effect relates to digital literacy, which has now become the focus towards addressing inequalities in the information society. The definition of digital literacy seems to vary in the literature, with authors providing general definitions that can apply to different domains of use. This was studied by Leahy and Dolan (2009), who provide a historical account of the defined meaning of digital literacy, before they settled on the definition provided by the European Union:

Digital Literacy involves the confident and critical use of Information Society Technology for work, leisure and communication. It is underpinned by Basic skills in ICT: the use of computers to retrieve, assess, store, produce, present and exchange information, and to communicate and participate in collaborative networks via the internet. (p. 152)

The definition by the European Union seems to be more specific towards the technical skill needed to use technology. Eshet-Alkalai (2004), on the contrary, speaks to more complex skills associated with digital literacy, such as cognitive, motoric, sociological and emotional - all needed to use digital environments effectively. He differentiates between five types of digital literacy, which can gradually develop over time through different exercises or knowledge transfer processes between project implementers, and project beneficiaries (government and citizens) (Leahy \& Dolan 2009). These include photo-visual literacy, reproduction literacy, branching literacy, information literacy and socio-emotional literacy (Eshet-Alkalai 2004). All these types possibly contribute to developing the digital citizen (Coldwell-Neilson 2017) - one who is able to purposefully and confidently communicate and find information to engage in processes to address some of their challenges.

When we interrogate the meaning of digital literacy in the field of DCE, there are key skills and knowledge that both citizens and government need to possess in order to effectively engage in the process. In this case, government and citizens do not only need to be digitally literate but also need to be civically literate (Henninger 2017). For digital literacy, what is paramount is that citizens have the capacity to find, retrieve, interpret and critically evaluate information provided on digital platforms. Civic literacy supports digital literacy in DCE, as citizens also possess the domain knowledge, ability and capacity to make sense of their political world and hence effectively act individually or collectively to hold government accountable and demand key services (Henninger 2017). Digital literacy applies to both government and citizens; however, civic literacy is more specific to citizens. Literature does not clearly articulate the domain literacy that governments should possess to effectively participate in DCE. This is quite typical in the field of citizen engagement, as the focus has mainly been on citizens, where initiatives have taken on an adversarial approach to implementation. However, recent literature has motivated for focusing on building the capacity for government responsiveness, to respond to citizen requests and engagement on digital platforms (Daskal 2018; Gigler \& Bailur 2014; Pade-Khene, Thinyane \& Machiri 2017; Peixoto \& Fox 2016). This is not a forthright process, and at times requires process re-engineering and an understanding of the valuable contribution of DCE, for government - any citizen engagement initiative is often looked at by government with suspicion to expose their ineffectiveness, rather than support their processes. That said, this research article proposes the consideration of responsiveness literacy specific to government. When we look at digital literacy in DCE, it does not exist as a general entity for technology use, but incorporates domain knowledge (Baykurt 2011) in relation to civic literacy (citizen) and responsiveness literacy (government) (see Figure 2).

Given the above conceptual framework of digital literacy, some of the challenges and failures of DCE projects relate to a lack of appropriate literacy in the above aspects. As a result, how can an individual or group become digitally literate if the means to do so are inaccessible and unusable (Leahy \& Dolan 2009) - is civic literacy and responsiveness literacy effectively embedded in the implementation process? Organisations that implement DCE initiatives need to embed informed processes of

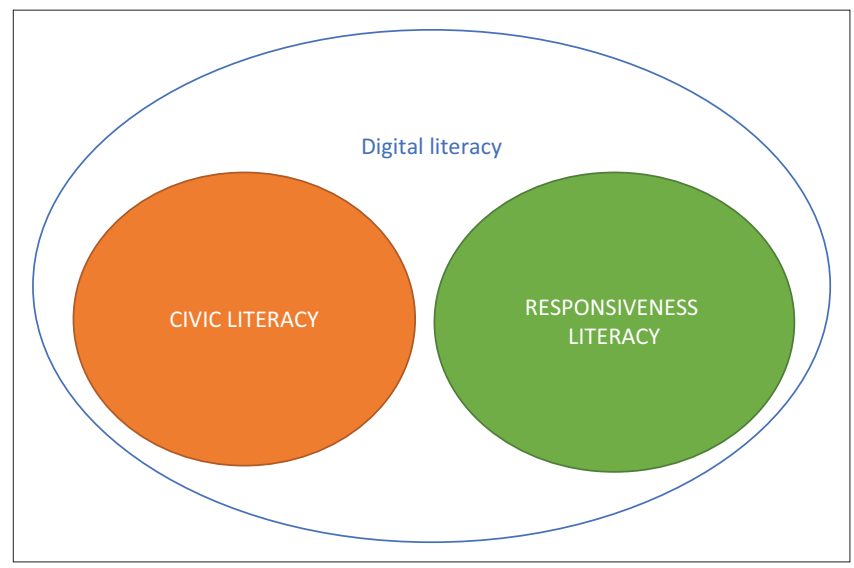

FIGURE 2: Reimagining digital literacy for digital citizen engagement. 
knowledge transfer between implementers and project beneficiaries to build digital literacy. However, each context is different, and hence, project implementers need to ensure that they are open to learning the endogenous practices of the context in order to understand digital literacy deficiencies and opportunities (Mansell 2011). These practices need to be applied iteratively and incrementally to address barriers and build digital literacy. The next sections reflect on this process using Szulanski's four-stage model in the MobiSAM case study.

\section{Research methodology}

The philosophical approach adopted for this research is pragmatism. This philosophy assists in disclosing the current practices associated with DCE initiatives in a local municipality and how these practices generate observations to understand the phenomenon (Creswell 2014). The pragmatist approach allows the researcher to focus their attention on the research problem, using various methods to gather information to address the problem. Observations and explanations of the actors in the research problem context allow for the development of knowledge around the aspect of DCE in a local municipality of South Africa. Goldkuhl (2012) discusses three types of pragmatism: referential, functional and methodological. The context of this research study focuses on the methodological pragmatism, where the researcher has actively participated in the context to provide suggestions and implement practices for improvement - in this case, building digital literacy. Pragmatism provides researchers with the ability to observe, understand, reflect and provide guidelines to mediate within a social context (Goldkuhl 2012; Saunders et al. 2009). The pragmatist philosophy has not been used significantly in research; however, it is instrumental in developing change and action, and how knowledge can relate to that action (Feilzer 2010; Morgan 2014). This is quite fundamental to developing theories within the African context (indigenous theory), as information systems theory is quite dominated by world views developed in different contexts western and business contexts (Mansell 2011). The premise of pragmatism is abductive reasoning, where the researcher engages in a process of developing a logical connection between theory and empirical data in an iterative fashion. Morgan (2014:1049) describes this as '.. an active process of inquiry that creates a continual back-and-forth movement between beliefs and actions'. Therefore, the data collection and analysis process in pragmatist research differs from typical positivist or interpretive research approaches. In this case, moving back and forth between induction and deduction, in an enquiry process of problem-solving, does not limit the researcher to a 'forced choice dichotomy between post positivism and constructivism' (Crewell \& Plano Clark 2007:27 in Feilzer 2010:8), restricted to a particular methodology or thought approach. Instead, in the context of uncertainty, particularly pertinent in DCE in South Africa, the knowledge character in pragmatism is constructive in the form of prescriptive knowledge (providing guidelines), normative knowledge (exhibiting values) and prospective knowledge (suggesting possibilities), which are built from descriptions and explanations in the enquiry process (Goldkuhl 2012). This is quite an emancipatory process, not only for the researcher but also for the research participants engaged in the process of problem-solving.

The research strategy applied is a case study to understand how digital literacy is developed in the knowledge process of a DCE initiative and why it was the suited approach (Yin 2009). The case study is MobiSAM, which is an initiative located in the Eastern Cape province of South Africa. MobiSAM provides a platform for two-way communication between local government and citizens on public service delivery issues. It is built on an operational model of iterative and incremental development, stakeholder engagement, strategy formulation and capacity building, comprehensive evaluation and citizen education (Pade-Khene et al. 2017). The MobiSAM technology incorporates both a reporting interface for citizens (via a mobile application [feature phone or smartphone], website and short message service [SMS]) and also a ticketing function (mainly used by the municipality to address internal communication challenges). MobiSAM presents a useful case study to demonstrate how knowledge was transferred between various stakeholders in the project (including the project implementation team), to build digital literacy among key beneficiaries - unit of analysis. This is still an ongoing process, as digital literacy development is gradual and uncertain, considering the factors that hinder DCE implementation, such as information poverty, lack of political commitment, digital exclusion, internet access and lack of incentive and motivation (Gigler, Bailur \& Anand 2014). Data were collected using a qualitative approach with the following tools:

- Interviews: Both semi-structured and unstructured interviews were applied, to allow understanding from the uncertain context to unfold, based on the experience of project participants. Government officials, citizens and project implementers were interviewed. Government officials interviewed included three service department managers, three communication and two customer care staff, three technicians, and two IT staff. Citizens interviewed included civil society representatives and community activists.

- Participant observation: The researcher participated in workshops and forums organised by the MobiSAM project, civil society and the local municipality. Examples of local government meetings included service management meetings, special council meetings and public forums on service delivery. Civil society forums and rights workshops were also organised to bring together various stakeholders in the municipality. Lastly, MobiSAM held public awareness meetings, needs assessment workshop, civil rights workshops, training a workshops and strategy formulation workshops.

- Document analysis: Documentation from the MobiSAM project was also analysed to supplement the field data. A baseline study report was reviewed to identify key communication ecologies and challenges in the municipality.

The case study is described in relation to the knowledge transfer process by Szulanski (1996), building explanations on 
the experiences of project stakeholders and the researcher as a key participant in the project. The analysis of data mainly relied on abductive reasoning, using Yin's (2009) analysis approach of explanation building. This approach builds an explanation about the case, developing causal links in an iterative manner. The iterative process was applied as follows:

- Re-examine the components of the knowledge transfer process proposed by Szulanski (1996).

- Compare the qualitative findings of the observation of the project implementation processes that incorporate knowledge transfer (consciously and unconsciously given uncertainty), against Szulanski's knowledge transfer model.

- Contextualise Szulanski's knowledge transfer process in the MobiSAM case - allowing for the emergence of an organic process of knowledge transfer in digital literacy development.

The above process was repeated at different phases of the project from early 2016 to mid-2017. To provide contextual background to the study and to build the analysis, the stakeholders of the project and their contribution to the knowledge transfer process are first identified and discussed in the case study description.

\section{Stakeholders of the MobiSAM project}

Stakeholders in the knowledge transfer process mainly consist of the project implementation team and key beneficiaries, that is, local government, citizens and civil society. Media also plays a key role in the DCE; however, at the current stage of the project, this article will not dwell on this particular stakeholder. All these stakeholders interact in a web of complexity and uncertainty in an environment that is politically influenced, as well as marginalised (Pade-Khene
\& Lannon 2017). Conflicting perspectives exist between stakeholders as well as within stakeholder groups - in this case, each group has a specific objective that they expect to achieve with MobiSAM. Building digital literacy requires that all stakeholders engage in a shared understanding of how a DCE can be effectively used and embedded in active citizenship practices and government responsiveness practices. The project manager of a DCE initiative needs to devise strategies to engage all key stakeholders (either separately or together), in an effort to learn how best the DCE initiative can function within its context. Table 1 provides a summary of conflicting aspects that emerge in different stakeholder groups in the MobiSAM project. It is important to know these to highlight the challenges that need to be overcome within the iterative process of knowledge transfer and digital literacy development. Table 1 also shows the literacy focus areas embedded in digital literacy for each group, with the exception of the project team that plays the role of source or facilitator (where knowledge exists within the beneficiary groups) of knowledge transfer.

\section{Knowledge transfer and digital literacy development in MobiSAM}

Knowledge transfer is a fundamental process for organisational learning in the business context. It emerges from the need to apply knowledge management as a key practice for maintaining and sharing key strategic knowledge on business operations. In the context of DCE, this mainly relates to managing knowledge that can be used by the community or key beneficiaries. Conger (2015) is known to be one of the few authors who contextualise knowledge management for ICT4D. In the context of ICT4D, knowledge managed is defined as a 'systematic process of acquisition, organisation, and communication of organisational member knowledge for reuse by others in the community' (Conger

TABLE 1: Conflicting aspects of each stakeholder group.

\begin{tabular}{|c|c|c|}
\hline Stakeholder & Conflicting aspects & Digital literacy focus areas \\
\hline Project Team & $\begin{array}{l}\text { Diverse mindsets and disciplines: The MobiSAM team has an advantage of being } \\
\text { diverse in terms of discipline and experience, as a citizen engagement project } \\
\text { requires diverse perspectives to be more holistic and relevant to the target } \\
\text { beneficiaries. } \\
\text { - However, project team members' views can clash, based on their backgrounds - } \\
\text { for example, some being task-orientated verses people-orientated, more technical } \\
\text { versus more social. }\end{array}$ & $\begin{array}{l}\text { - Mainly the source of building digital literacy. } \\
\text { - However, the role does oscillate between a source and facilitator of } \\
\text { knowledge transfer for developing digital literacy for digital citizen } \\
\text { engagement. } \\
\text { - Diversity of skill is paramount in this groups - hence, working towards a } \\
\text { shared understanding to implement digital citizen engagement is } \\
\text { important. } \\
\text { - Context literacy later emerges as a focus area, but not necessarily as part } \\
\text { of digital literacy. }\end{array}$ \\
\hline Citizens & $\begin{array}{l}\text { Divided social and economic aspects: This is such a loaded aspect; however, } \\
\text { perspectives between different groups such as the youth, women, men and } \\
\text { elderly can conflict. } \\
\text { - In the case of South Africa, income inequalities are still real, and the history of } \\
\text { apartheid has different groups in very dire living circumstances. } \\
\text { - What is paramount to one citizen may be different for another. Coupled with this } \\
\text { is a complete lack of trust in government, because of a lack of government } \\
\text { responsiveness that has plagued local municipalities in marginalised contexts. }\end{array}$ & - Focus area embedded in digital literacy is Civic Literacy. \\
\hline Civil Society & $\begin{array}{l}\text { - Conflicting goals and representations: Civil Society in Makana Municipality is } \\
\text { quite divided and not enough collaboration exists; yet, they typically share many } \\
\text { goals. Furthermore, it is typically observed that they have an agenda to hold } \\
\text { government to account, rather than collaborate, being sensitive to the } \\
\text { constraints of government. } \\
\text { - A shared goal needs to be nurtured and facilitate among CSOs. }\end{array}$ & - Focus area embedded in digital literacy is Civic Literacy. \\
\hline Government & $\begin{array}{l}\text { - Political influence and resource constraints: Part of the local municipality is } \\
\text { politically controlled and the other is administratively managed. } \\
\text { - As a result, some decisions are based on political agendas. Furthermore, local } \\
\text { municipalities are resource-constrained because of ineffective planning - some } \\
\text { staff who try to work effectively are constrained by this and feel that citizens do } \\
\text { not understand the challenges experienced. }\end{array}$ & - Focus area embedded in digital literacy is Responsiveness Literacy. \\
\hline
\end{tabular}


2015:114). Organisational learning is closely linked to the process of developing digital literacy for citizens and government. Here, organisational learning refers to 'internal adaptation processes triggered by some kind of disjunction or unease in the relationship between the organisation and what lies external and challenging to it in its environment' (Spender 2008:160). Digital literacy aims to build the capacity of citizens and government to effectively participate in DCE this can be performed through a process of learning, training and engagement. For digital literacy to develop in the MobiSAM project, it had to undergo a process of learning, unlearning and knowledge transfer. This process is not necessarily linear, but iterative to adapt to changes in the complex and uncertain context. Szulanski's (1996) four-stage model presents a process that is used to describe the process of knowledge transfer in the MobiSAM case - in describing this process, key features and practices of digital literacy development at each stage are identified. Knowledge transfer occurs through the dyadic exchange of knowledge between a source and recipient. For each stakeholder identified in Table 1 , the role of 'source' and 'recipient' is interchangeable, depending on the knowledge shared. The four stages include initiation, implementation, ramp-up and integration:

- Initiation - As the first step in the process, this consists of events that lead to a decision to transfer knowledge. In this case, the need for knowledge transfer to support DCE is identified, as well as the feasibility of such an initiative. The constraints of the possible implementation of a DCE initiative are also explored in the context. In the MobiSAM case study, the project team needed to explore the status of digital literacy, including civic literacy and responsiveness literacy in the context. This is based on the understanding of the communication ecologies of citizens and government in relation to civic participation and responsiveness to service delivery reporting. Abaseline study was conducted, which consisted mainly of two surveys: the first survey was distributed to citizens and the second survey was distributed to local government staff. This survey explored the existing approaches for communication and citizen participation, identifying traditional ways of engagement and the use of technology for engagement between government and citizens. In addition to the survey, the project team engaged in workshops, informal interviews and government public forums to understand the status of digital literacy, civic literacy and responsiveness literacy. After the baseline study, a needs assessment was conducted to explore the key needs related to the use of technology for citizen engagement and possible constraints. This was a more focused exercise, in relation to the purpose of MobiSAM, to provide a platform for social accountability monitoring. The purpose of this stage was to therefore explore the needs for digital literacy development and the feasibility of building digital literacy in the project implementation process. This stage is not static and once off, as demand-driven needs can emerge as the MobiSAM project is adopted in the context. In this case, a needs assessment can be reintroduced in project activities to reevaluate existing digital literacy needs in the project.
- Implementation - This is the stage where the transfer of knowledge begins, and resources flow between the source and recipient. The project team acts as a source of knowledge for developing digital literacy; however, they also become a recipient of new knowledge from citizen and governments that shapes their activities to develop digital literacy for the context. As a recipient of knowledge, they begin to understand protocol, legislation, accountability processes, transparency requirements, local culture and so on that govern the process of local citizen engagement. An understanding of these aspects shapes their programme for guiding the development of digital literacy to effectively use MobiSAM platforms. In this case, government, citizens and civil society become the source of knowledge transfer, playing an interactive game of learning and informing. The MobiSAM project team also played the role of facilitator, in enabling an understanding of how to effectively integrate and use the MobiSAM platform. This was applied through strategy formulation workshops with citizens and government (separately and then jointly to manage conflicting views), meetings with municipal management staff and CSO leadership, engaging in the revision of the municipal communication strategy, civic education and adaptive ICT training on how to use MobiSAM platforms. An important aspect is that social ties begin to develop between source and recipient, and stakeholders work towards a mutual understanding of how MobiSAM can best work in Makana Municipality. Szulanski (1996) articulates this as follows:

The transferred practice is often adapted to suit the anticipated needs of the recipient, to pre-empt problems experienced in a previous transfer of the same practice, or to help make the introduction of new knowledge less threatening to the recipient. (p. 29)

Initial understanding and development of digital literacy is enabled during this stage of knowledge transfer. Furthermore, the project team begins to understand contextual dynamics of both government and citizens, hence context literacy (endogenous practice) - the competence or knowledge to interact and engage in these spheres (Mansell 2011). The implementation stage stops, when project beneficiaries begin to use the gained knowledge on digital literacy.

- Ramp-up: This is the stage when the recipients of knowledge begin to use the new knowledge in the context. This was the stage that citizens began to see the value of the MobiSAM platforms and engage via the Facebook page, email, SMS and the MobiSAM website. In relation to the citizen, additional civic education workshops had to be held with civil society, media, local schools and development centres in Makana Municipality. Furthermore, the project had hired ward liaisons in the community to impart awareness and knowledge of MobiSAM, and based on the train-the-trainer model, train local community members in their wards to use the various platforms effectively. The value of a new initiative 
can sometimes only be seen and understood from the perspective of common members of a networked system, whether it is the youth, woman support networks or schools. Therefore, MobiSAM activities attempt to incorporate key actors involved in these networks in order to maximise on participation. This has been a very challenging process, as the process of building digital literacy for DCE is often met with resistance and lack of resources to support development. This is clearly evident from Figure 3, which is a map of reported issues - the reported issues are centred on a particular location in Makana Municipality (more affluent areas), which is closer to the centre of town and the local university.

- It is important that unexpected problems or barriers are identified that hinder the alignment of transferred knowledge and expected performance of the adapted practices (Szulanski 1996). This is no different for local government. Local government staff strategised for the integration of MobiSAM in Makana Municipality and participated in workshop sessions to re-engineer their existing processes to adapt better communication practice with MobiSAM. This was successful among some municipal staff, who confessed that they now saw the value of feedback in communicating with citizens, based on the development of their digital literacy around government responsiveness. Their original system, identified in the initiation stage, showed how broken their communication ecology was, with a lack of feedback culture and engagement with citizens. Nonetheless, MobiSAM was met with much resistance from some municipal staff - requiring the MobiSAM project team to rethink their implementation approach to address the existing constraints. Some social and organisational culture constraints may be beyond the scope of MobiSAM

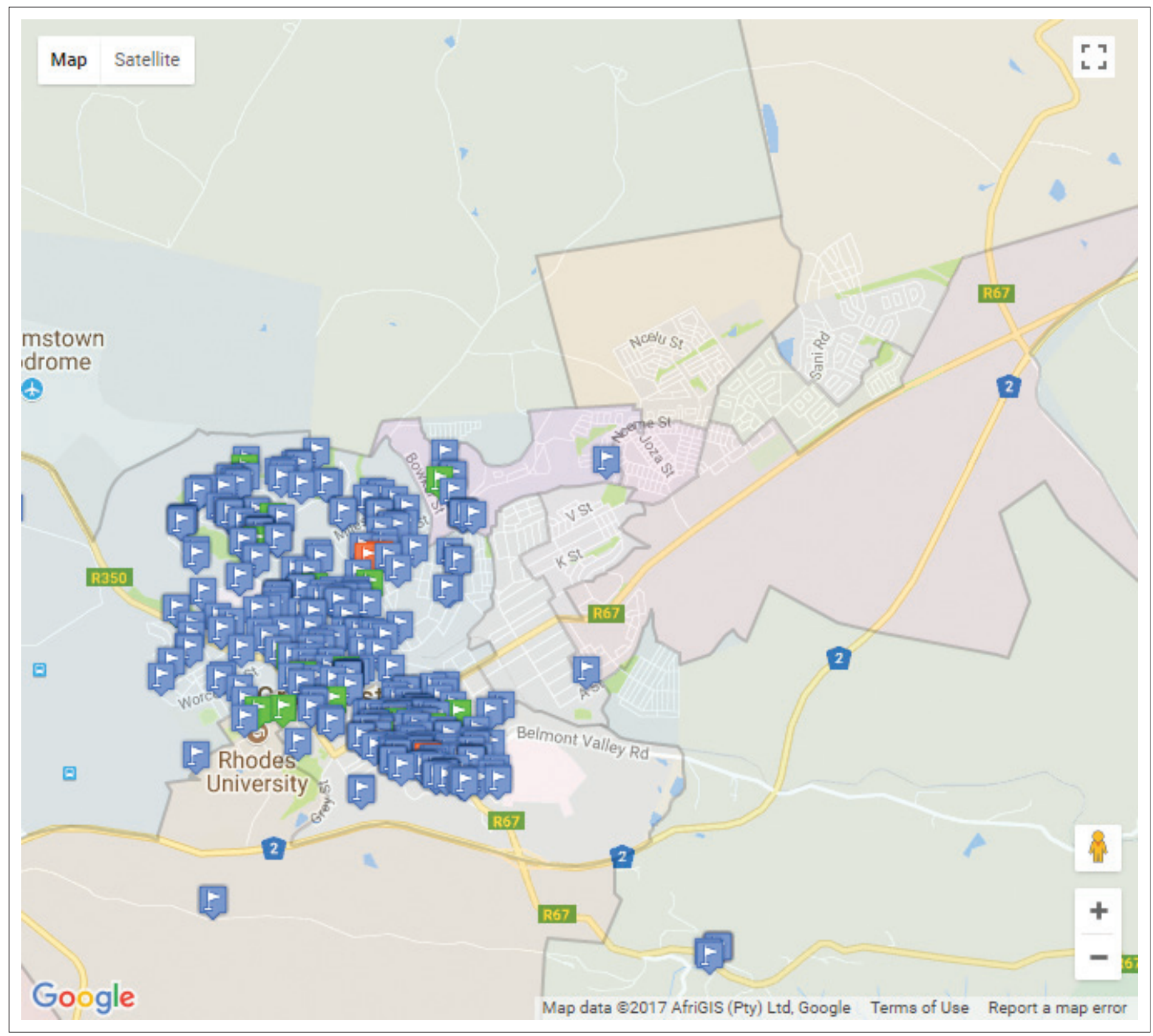

Source: MobiSAM Website, 2018, Active service delivery issues, MobiSAM, viewed 05 June 2018, from https://mobisam.net/

FIGURE 3: Map of reported service delivery issues in Makana Municipality. 
TABLE 2: A summary of the knowledge transfer process of digital literacy development.

\begin{tabular}{|c|c|c|}
\hline Stage & Practices & Digital literacy focus \\
\hline Initiation & Baseline study, needs assessment and relationship building. & Explore \\
\hline Implementation & $\begin{array}{l}\text { - Strategy formulation, meetings with municipal management staff and CSO leadership, } \\
\text { - engaging in the revision of the municipal communication strategy, } \\
\text { - adaptive training on how to use MobiSAM platforms and civic education workshops. }\end{array}$ & Enable \\
\hline Ramp-up & $\begin{array}{l}\text { - Awareness and knowledge campaigns, continued process re-engineering support for local government and continued support for civil } \\
\text { society engagement. }\end{array}$ & Engage \\
\hline Integration & $\begin{array}{l}\text { - Demand-driven needs assessment, continued support for government and citizens and evaluation to understand existing constraints to } \\
\text { complete integration. }\end{array}$ & Embed \\
\hline
\end{tabular}

Source: Adapted from Szulanski, G., 1996, 'Exploring internal stickiness: Impediments to the transfer of best practice within the firm', Strategic Management Journal 17, 27-43. https://doi. org/10.1002/smj.4250171105

practices; nonetheless, formulating key partnerships with other government officials and CSOs may push for the transformation of current practice in the municipality. In relation to building digital literacy, this stage relates to engaged literacy development.

- Integration: This stage is reached when digital literacy is developed and institutionalised in government and civil society practice, as well as becoming an embedded skill of active citizens. Satisfactory results of the existence of digital literacy should begin to emerge. Certain practices related to interaction with evidence-based data for citizen engagement and government responsiveness become associated with various actors, departments and individuals. As digital literacy showed initial progress in becoming embedded, MobiSAM became formerly integrated into the municipality communication strategy. The project team is always invited to participate in key strategic forums of the municipality, as digitally literate government staff engage in discussions and practices around using MobiSAM, and the data generated from it. Citizens have also began to use MobiSAM as a point of call for reporting issues, perusing the digital platform for similarly reported issues to engage in discussion about them with an understanding of the severity of the issue. Civil societies such as the Grahamstown Residents Association (GRA), Public Accountability Monitor (PSAM) and Black Sash (BS) now invite MobiSAM as a strategic partner into their civic workshops. The evidence gathered from the technology platforms is often used by the GRA to follow up on unaddressed issues or to lobby for key services. Despite the many benefits of having reached a level of digital literacy with some stakeholders, there are still issues of 'stickiness' that hinder the effectiveness of the process and call for a continuous iterative approach, building on the lessons learned from each of the stages of knowledge transfer. Therefore, this process should not be linear, but lessons learned should feed into another staged iteration of initiation to explore emerged aspects of digital literacy and citizen engagement.

Table 2 provides a summary of the knowledge transfer process of digital literacy development in the MobiSAM DCE project. Various practices emerged that can guide each stage of literacy development - practices indicated in Table 2 are suggestions, but not limited to these, as practitioners or researchers may apply different approaches within the constraints of the project and context. Nonetheless, this
TABLE 3: A comparison of information and communication technology for development differentials and aspects of stickiness.

\begin{tabular}{ll}
\hline Toyama differentials & Szulanski's aspects of 'stickiness' \\
\hline Access & - Barren organisational context \\
Capacity & - Lack of absorptive capacity \\
Motivation & - Lack of retentive capacity \\
& - Lack of motivation from the source of knowledge \\
& - Lack of motivation to receive knowledge \\
& - Arduous relationship between stakeholders \\
\hline
\end{tabular}

Note: Please see the full reference list of the article, Pade-Khene, C., 2018, 'Embedding knowledge transfer in digital citizen engagement in South Africa: Developing digital literacy', Reading \& Writing 9(1), a193. https://doi.org/10.4102/rw.v9i1.193, for more information.

provides a starting point from which to build on. What was also identified in the knowledge transfer process was the digital literacy development focus at each stage of the transfer process. In this case, digital literacy developed through a Quadruple-E process of: (1) explore, (2) enable, (3) engage and (4) embed.

The transfer of knowledge is likely to experience what Szulanski (1996) refers to as internal 'stickiness', which is based on the characteristics of knowledge transferred, the source of the knowledge, recipients of the knowledge (Ajmal \& Koskinen 2008) and the context (Ajmal \& Koskinen 2008; Yeh, Lai \& Ho 2006). Pade-Khene and Lannon (2017) relate this to the issue of power and political influence in DCE diverse stakeholder perspectives and conflicting views result in the need for ad hoc solutions as problems emerge in the transfer process. Nonetheless, Orlikowski (2002:271) argues that it is a gradual process of developing 'know-how' in the transfer process, so as to understand the origins of stickiness in order to work around them and maximise on digital literacy development. The issues of stickiness are not foreign to the ICT4D field and hence relate a lot to Toyama's three differentials that influence digital implementation in developing countries (see Table 3). Project stakeholders need to be aware of these and mitigate their influence in the knowledge transfer process.

\section{Conclusion}

The research study presents a case for developing digital literacy in DCE initiatives. This is pertinent as DCE has emerged as a key tool in supporting two-way communication between citizens and government. It also contributes to building evidence-based data that can be used to support social accountability and transparency practices. The article identifies that DCE is not a straightforward process, where some factors that hinder progress relate to a lack of effectively building digital literacy among citizens and 
government as project beneficiaries. In the case of DCE, digital literacy does not only relate to the technical ability to use ICTs but also relate to embedded competence in civic literacy and responsiveness literacy. Using Szulanski's (1996) four-stage process of knowledge transfer, the MobiSAM project is reflected on in terms of the practices applied to transfer knowledge and develop digital literacy of its stakeholders. The process was identified as iterative and incremental in nature, with key focus areas for digital literacy at the different stages, that is, the Quadruple-E process of (1) explore, (2) enable, (3) engage and (4) embed. Despite the benefits of knowledge transfer, this process is affected by factors that hinder progress, referred to as 'stickiness'. The aspects identified relate closely to differentials of ICT4D proposed by Toyama (2011) - this highlights the significance of addressing digital access, motivation and capacity in developing digital literacy; and having DCE classified within the field of ICT4D. The process for knowledge transfer and developing digital literacy that was identified in this article can provide a guideline for future implementation of DCE initiatives in resource-constrained contexts.

\section{Acknowledgements}

This research was funded by the National Research Foundation of South Africa and the 'Making All Voices Count' initiative. The researcher also thank the MobiSAM team for their continued support and participation in the project, and generation of practical experience to reflect on.

\section{Competing interests}

The author declares that she has no financial or personal relationships that may have inappropriately influenced her in writing this article.

\section{References}

Ajmal, M. \& Koskinen, K., 2008, 'Knowledge transfer in project-based organisations: An organisational culture perspective', Project Management Journal 39, 7-15. https://doi.org/10.1002/pmj.20031

Algotsson, E., Murombo, T., Davis, M. \& Poole, M., 2009, Water supply and sanitation in South Africa: Environmental rights and municipal accountability, Lawyers for Human Rights, Cape Town.

Baykurt, B., 2011, 'Redefining citizenship and civic engagement: political values embodied in FixMyStreet.com.', pp. 1-18, presented at the Selected Papers of Internet Research (SPIR), Seattle, WA

Coldwell-Neilson, J., 2017, 'Assumed digital literacy knowledge by Australian universities: Are students informed?', in Proceedings of the Nineteenth Australasian Computing Education Conference, presented at the Australasian Computing Education Conference, ACM, Geelong, Australia, 31 January to 3 February 2017, pp. 75-80.

Conger, S., 2015, 'Knowledge management for information and communication technologies for development programs in South Africa', Information Technology for Development 21, 113-134. https://doi.org/10.1080/02681102.2014.899960

Creswell, J.W., 2014, A concise introduction to mixed methods research, 1st edn., Sage, Thousand Oaks, CA.

Daskal, E., 2018, 'Let's be careful out there...: How digital rights advocates educate citizens in the digital age', Information, Communication \& Society 21, 241-256. https://doi.org/10.1080/1369118X.2016.1271903

Dodson, L., Sterling, S. \& Bennett, J., 2012, 'Considering failure: Eight years of ITID research', Information Technologies and International Development 9, 19-34. https://doi.org/10.1145/2160673.2160681

Eshet-Alkalai, Y., 2004, 'Digital literacy: A conceptual framework for survival skills in the digital era', Journal of Educational Multimedia and Hypermedia 13 93-106.
Evans, A.M. \& Gomes, R.G., 2017, 'The role of digital literacy in citizens' adoption of digital public services: The Portuguese case', in Proceedings of the 17th European conference on digital government, presented at the 17th European Conference on Digital Government, Academic Conferences and Publishing International Limited Digital Government, Academic Conferences and Pis
Lisbon, Portugal, 12-13 June, 2017, pp. 71-77.

Feilzer, M.Y., 2010, 'Doing mixed methods research pragmatically: Implications for the rediscovery of pragmatism as a research paradigm', Journal of Mixed Methods Research 4, 6-16. https://doi.org/10.1177/1558689809349691

Gaventa, J. \& Barrett, G., 2012, 'Mapping the outcomes of citizen engagement', World Development 40, 2399-2410. https://doi.org/10.1016/j.worlddev.2012.05.014

Gigler, B., Bailur, S. \& Anand, N., 2014, 'The loch ness model: Can ICTs bridge the “Accountability Gap"?', in B. Gigler \& S. Bailur (eds.), Closing the feedback loop: Can technology bridge the accountability gap?, pp. 211-278, The World Bank, Washington, DC.

Gigler, B.-S. \& Bailur, S. (eds.), 2014, Closing the feedback loop: Can Technology bridge the accountability gap? Directions in development, The World Bank, Washington, DC.

Goldkuhl, G., 2012, 'Pragmatism vs interpretivism in qualitative information systems research', European Journal of Information Systems 21, 135-146. https://doi. org/10.1057/ejis.2011.54

Haikin, M., Bailur, S., Berdou, E., Dudding, J., Lopes, C.A. \& Belcher, M., 2016 Evaluating digital citizen engagement: A practical guide, The World Bank, Washington, DC

Henninger, M., 2017, 'Government information: Literacies, behaviours and practices', Government Information Quarterly 34, 8-15. https://doi.org/10.1016/j.giq.2016. 12.003

Huerta, E. \& Sandoval-Almazan, R., 2007, 'Digital literacy: Problems faced by telecenter users in Mexico', Information Technology for Development 13, 217232. https://doi.org/10.1002/itdj.20071

Ika, L. \& Hodgson, D., 2014, 'Learning from international development projects: Blending critical project studies and critical development studies', International Journal of Project Management 32, 1182-1196. https://doi.org/10.1016/j. ijproman.2014.01.004

Leahy, D. \& Dolan, D., 2009, 'Digital literacy - Is it necessary for inclusion', in A. Holzinger \& K. Miesenberger (eds.), $\mathrm{HCl}$ and usability for e-inclusion, Lecture Notes in Computer Science, pp. 149-158, Springer, Berlin, Heidelberg.

Mansell, R., 2011, 'Power and interests in information and communication and development: Exogenous and endogenous discourses in contention', Journal of International Development 26, 109-127. https://doi.org/10.1002/jid.1805

MobiSAM Website, 2018, Active service delivery issues, MobiSAM, viewed 05 June 2018, from https://mobisam.net/

Morgan, D.L., 2014, 'Pragmatism as a paradigm for social research', Qualitative Inquiry 20, 1045-1053. https://doi.org/10.1177/1077800413513733

Nnadozie, R.C., 2013, 'Access to basic services in post-apartheid South Africa: What has changed? Measuring on a relative basis', The African Statistical Journal 16, 81-103.

Orlikowski, W.J., 2002, 'Knowing in practice: Enacting a collective capability in distributed organising', Organisation Science 13, 249-273. https://doi. org/10.1287/orsc.13.3.249.2776

Pade-Khene, C. \& Lannon, J., 2017, 'Learning to be sustainable in ICT for development A citizen engagement initiative in South Africa', presented at the 14th International Conference on Social Implications of Computers in Developing Countries (IFIP 9.4 WG), Yogyakarta, Indonesia, 22-24 May 2017.

Pade-Khene, C., Thinyane, H. \& Machiri, M., 2017, 'Building foundations before technology: An operation model for digital citizen engagement in resource constrained contexts', presented at the 17th European Conference on Digital Government, Lisbon, Portugal, 15-16 June.

Peixoto, T. \& Fox, J., 2016, When does ICT-enabled citizen voice lead to government responsiveness?, World Bank, Washington, DC

Saunders, M.N.K., Lewis, P., Thornhill, A. \& Wang, C.L., 2009, 'Analysing quantitative data', in M.N. Saunders, P. Lewis \& A. Thornhill (eds.), Research methods for business students, pp. 414-479, Prentice Hall, UK.

Spada, P., Mellon, J., Peixoto, T. \& Sjoberg, F.M., 2015, Effects of the Internet on participation: Study of a public forum referendum in Brazil, World Bank, Washington, DC

Spender, J.C., 2008, 'Organisational learning and knowledge management: Whence and whither?', Management Learning 39, 159-176. https://doi. org/10.1177/1350507607087582

Szulanski, G., 1996, 'Exploring internal stickiness: Impediments to the transfer of best practice within the firm', Strategic Management Journal 17, 27-43. https://doi. org/10.1002/smj.4250171105

Tissington, K., Dettmann, M., Langford, M., Dugard, J. \& Content, S., 2008, Water services fault lines: An assessment of South Africa's water and sanitation provision across 15 municipalities, Center for Applied Legal Studies, University of Witwatersrand, Johannesburg.

Toyama, K., 2011, 'Technology as an amplifier in international development', presented at the Proceedings of the iConference, pp. 75-82, ACM, Seattle, WA 8-11 February.

Toyama, K., 2015, Geek Heresy, Public Affairs, New York.

Yeh, Y., Lai, S. \& Ho, C., 2006, 'Knowledge management enablers: A case study', Industrial Management \& Data Systems 106, 793-810. https://doi. org/10.1108/02635570610671489

Yin, R.K., 2009, Case study research: Design and methods, Sage, Thousand Oaks, CA. 